\title{
Participación ciudadana en la formulación de políticas públicas locales, el caso del distrito VI del Municipio de Managua (2007-2013)
}

\author{
Rodolfo Morales
}

Universidad de Chile

\section{Resumen}

Este estudio de caso analiza los procesos de participación ciudadana en la formulación de las políticas públicas locales y las interrelaciones de la ciudadanía con el Distrito VI del municipio de Managua, en el periodo 2007-2013. Específicamente, se examina cómo funciona y se operativiza el marco del nuevo modelo de participación ciudadana (Gabinetes de la Familia la Comunidad y la Vida) implementado por decreto presidencial 112 -2007, y la manera en que estos contribuyen desde el distrito a los diseños de políticas públicas locales. Esta investigación corresponde a un caso único y fue desarrollada a partir de un enfoque cualitativo de tipo descriptivo. Se observa un proceso de participación que se construye desde las bases territoriales, con una organización relativamente joven y en evolución, que funciona como un mecanismo de articulación y gestión institucional para adecuar la oferta pública a las necesidades de las comunidades. Se reconoce el aporte de la participación ciudadana y la idea de un gobierno relacional, que implica a la ciudadanía en las decisiones. No obstante, pese al involucramiento de la ciudadanía en los temas sociales, esta aún se ubica en el nivel de información y consulta, puesto que los gabinetes comunitarios funcionan como facilitadores de información y los insumos para que la alcaldía tome su mejor decisión.

Palabras clave: Participación ciudadana, gobierno local, incidencia en políticas públicas.

Citizen participation in the formulation of local public policies, the case of district VI of the Municipality of Managua (2007-2013)

\begin{abstract}
This study case analyzes the processes of citizen participation in the formulation of local policies and interrelationships of citizenship with the District VI of the municipality of Managua, in the period 20072013. Specifically, it discusses how the new model for citizen participation ("Gabinetes de la Familia, la Comunidad y la Vida"), implemented by Presidential Decree 112 -2007, works and is operationalized, and how it contributes to designs local public policies. This research corresponds to a single case and was developed from a qualitative descriptive approach. A participatory process that is built from the territorial bases, with a relatively young and evolving organization, which functions as a hinge mechanism and institutional management to bring public services to the needs of communities is observed. The contribution of citizen participation and the idea of a relational government, involving the citizens in decisions is recognized. However, despite the involvement of citizens in social issues, this is still in the level of information and consultation, as the community work like facilitators of information and inputs, so the government can make the best decision.
\end{abstract}

Keywords: Citizen participation, local government, public policy advocacy. 


\section{Introducción}

La participación ciudadana favorece la generación de capacidades en sujetos y organizaciones comunitarias, con el objetivo de que puedan debatir y participar en la toma de decisiones. Según Fernández (2006), en este espacio se hace posible "el encuentro entre ciudadanos y sus gobernantes y entre las necesidades de la población y las decisiones de la autoridad".

En Nicaragua, los Consejos del Poder Ciudadano o Gabinetes de la Familia de la Comunidad y la Vida son el marco del nuevo modelo de participación ciudadana, implementado por el gobierno del Frente Sandinista por decreto presidencial 1122007. Este modelo de participación ciudadana, ha sido el producto de un proceso de acumulación de experiencias, que tuvo su origen con el triunfo de la Revolución Popular Sandinista en 1979, la cual se inició en términos normativos, con la promulgación de la Constitución de $1987^{1}$, que restauró la autonomía municipal suprimida por la dictadura somocista en 1937. Se considera como marco referencial, la creación e implementación de la ley de municipio (Ley № 40, aprobada en el año 1987 y puesta en vigencia en el año 1990) y la ley de participación ciudadana (Ley № ${ }^{0}$ 475, aprobada en el año 2003); instrumentos normativos que han fortalecido el andamiaje jurídico, propiciando un incremento cuantitativo y cualitativo de la participación ciudadana en la gestión local para la formulación, implementación y evaluación de las políticas públicas locales.

Este estudio de caso pretende precisar los elementos que definen los procesos de participación ciudadana en el municipio de Managua, particularmente en el Distrito VI de la capital. Se trata de desentrañar y conocer el entramado de las relaciones que se efectúan entre los distintos actores de la sociedad civil e institución municipal, que legitiman o sustenta la formulación de las políticas públicas que emanan de la delegación del Distrito VI de la Alcaldía de Managua.

Cabe mencionar que la efectividad de este modelo ha sido muy cuestionada en términos de legi-

\footnotetext{
${ }^{1}$ En el Artículo 48 de la Constitución, se reconoce la "obligación del Estado eliminar los obstáculos que impidan de hecho la igualdad entre los nicaragüenses y su participación efectiva en la vida política, económica y social del país". Los ciudadanos tienen derecho de participar en igualdad de condiciones en los asuntos públicos y en la gestión estatal, a nivel nacional y local (Art.50).
}

*Dirección de correspondencia [Correspondence address]: Rodolfo Morales, Universidad de Chile

E-mail: ecojr2003@yahoo.com timidad, en cuanto a aspectos normativos y aceptación por los diferentes actores sociales ${ }^{2}$, que han impulsado procesos y mecanismos de participación ciudadana tanto a nivel municipal, regional y nacional.

En este sentido, el objetivo de esta investigación es analizar el proceso de participación ciudadana en la formulación de las políticas públicas locales y las interrelaciones de la ciudadanía con el Distrito VI del municipio de Managua, en el periodo 2007-2013. Considerando, según lo planteado por Serra Vásquez (2010), que uno de los problemas más importantes en los procesos de participación ciudadana son los espacios limitados para una participación efectiva, en tanto los líderes comunitarios no cuentan con información y conocimiento previo de las propuestas institucionales, no permitiéndoles consultar con sus bases, analizar las propuestas y llevar un planteamiento consensuado ante al gobierno municipal.

\section{Enfoque teórico de la participación}

La Participación es un concepto polisémico, relativamente reciente, que carece de una conceptualización unívoca y que se vincula a categorías teóricas como ciudadanía, Estado, Democracia, sociedad civil, entre otras, donde abundan posiciones teóricoprácticas muchas veces en abierta contradicción; es decir, se presenta con una "alta carga valorativa" (Baño, 1997). Nuria Cunill Grau (2004) comprende la participación como la intervención de los particulares en las actividades públicas, en tanto son portadores de intereses sociales, donde la variable básica es el tipo de relación que se establece entre los individuos y el Estado (Mlynarz et al., 2011). Vista así, la participación se enmarca en una acción colectiva con cierto grado de organización, que adquiere sentido al orientarse en una decisión colectiva (Rodríguez, 2007). Flisfisch (1980) agrega que los mecanismos de decisión colectiva suponen dos elementos: un conjunto de reglas que determinen los criterios de membrecía en el proceso de decisión; y una regla de agregación de las decisiones individuales que concurren a la formación de la voluntad colectiva.

La participación "abarca múltiples escalas y espacios" (Hopenhayn, 1988), como los espacios políticos, económicos, sociales, culturales, entre otros, con escalas que son determinadas según su alcance nacional, regional o local; o en términos de Boeninger (1984), en macro, meso o micro parti-

\footnotetext{
${ }^{2}$ Organismos no Gubernamentales como la Coordinadora Civil, IPADE, FUPADE, INGES, entre otras, Partidos Políticos de Oposición y Medios de comunicación.
} 
cipación. El primer ámbito corresponde al espacio propiamente político donde se adoptan decisiones que comprometen el destino de la colectividad en su conjunto. Se trata del desarrollo de procesos que determinan el orden público y en los que se invocan intereses de carácter general. La meso participación ${ }^{3}$ tiene por objeto las políticas sociales de alcance sectorial o regional, que afectan a amplios conglomerados, pero no comprometen la esencia del régimen político. Finalmente, la micro participación tiene relación con el destino cotidiano de individuos y grupos pequeños, en donde las decisiones siguen siendo de algún modo políticas que no ejercen gravitación sobre el devenir político de la comunidad global.

El ejercicio participativo o de ciudadanía presupone algunas condiciones, como la pertenencia a una comunidad política (Molina, 1997); que existan instituciones y mecanismos que regulen, articulen, concierten y negocien la pluralidad de intereses presentes en la sociedad; la existencia de sujetos libres y conscientes de sus derechos, capaces de poner en juego sus demandas e intereses y dispuestos a ejercer influencia en las decisiones públicas que se derivan de los espacios de ejercicio de su propia ciudadanía; y, por último, la existencia de un espacio público de interacción, en donde se confrontan, negocian y validan diferentes intereses. Sergio Micco (1997) señala que los conceptos de ciudadanía y de participación están íntimamente ligados a la idea de derechos individuales y a la noción de pertenencia a la comunidad política.

Presentadas algunas conceptualizaciones sobre participación ciudadana, para efectos de este trabajo, entenderemos la participación ciudadana como la relación que existe entre instituciones del Estado, por una parte; y los movimientos, asociaciones y organizaciones sociales que representan y expresan los intereses de los ciudadanos; lo que implica un proceso de interacción social entre grupos con poder formal y los que carecen de él. En este sentido, la participación es ante todo una expresión histórica y social del ejercicio de la ciudadanía (Campero, 2013).

\section{Nociones de ciudadanía}

La ciudadanía refiere a la estructura de derechos y responsabilidades de las personas en su relación con el Estado y la comunidad política (Serrano, 1998). En la construcción histórica de esta relación, se han desarrollado tres clases de derechos (Mars-

\footnotetext{
${ }^{3}$ Este concepto no es utilizado por Boeninger, pero ayuda a connotar el espacio intermedio que existe entre la participación política y la participación social.
}

hall, 1998): i) Derechos civiles o ciudadanía civil; ii) Derechos políticos o ciudanía política; y iii) Derechos sociales. Estas tres clases de derechos aseguran un nivel de bienestar mínimo. Sin embargo, esta definición genera un escenario pasivo de lo que es ser ciudadano, dando pie a una crítica que demanda una perspectiva que entienda la ciudadanía como un ejercicio activo en donde los ciudadanos demandan derechos y no solo los aceptan (Kymlicka, 1996). En este sentido el concepto de ciudadanía activa nos remite hacia una noción más viva de la ciudadanía, dado que participar significa que la gente sea capaz de estar activamente presente en los procesos de toma de decisiones que atañen al colectivo (Mujica, 2005). Sin embargo, para el ejercicio de la ciudadanía, se requiere que los miembros de la sociedad estén premunidos de ciertos derechos que les permitan incidir en las instituciones del Estado, en la toma de decisiones o en la realización de determinadas políticas (Castillo, 1997). De esta manera, puede distinguirse entre "ciudadanía sustantiva" y "ciudadanía formal", entendiendo los derechos ciudadanos como un campo de lucha sociopolítica entre grupos sociales con intereses contrapuestos (Bottomore, 1992).

Se hace necesario, entonces, avanzar hacia un equilibrio entre los derechos individuales y las responsabilidades sociales, bajo el paraguas de la noción de ciudadanía en donde se "reconozca a la sociedad civil como el locus natural en donde se generan los espacios para que los ciudadanos puedan ejercer activamente estos derechos y responsabilidades" (Paredes, 2007), generando un valioso capital social, que debe ser entendido como un capital comunitario, auto-producido por un grupo o una comunidad local; que libera un potencial acumulado por sus propias acciones y experiencias; un cúmulo de conjunciones que producen una fuerza de identidad que pervive a toda exterioridad (Salazar, 1998 citado en Paredes, 2007: 11).

\section{Participación y Democracia}

Una de las bases fundamentales del sistema democrático es el voto, que dependiendo de cómo se ejerza, da origen a 3 tipos de formas democráticas: i) Democracia indirecta; ii) Democracia semi directa; y iii) Democracia directa.

La democracia representativa es una forma democrática indirecta, que supone la delegación del poder (o soberanía) por parte del pueblo sobre la figura de autoridades (representantes) que son electas, de forma periódica, libre, secreta e informada. Por otro lado, implica necesariamente la cesión de poder (por parte de los electores) y por tanto se 
precisa que exista una vinculación simétrica y congruente entre los que gobiernan y los ciudadanos (Held, 1991). Es decir, que los representantes electos representen los intereses, opiniones y proyectos de los ciudadanos. (Falabella, 2008)

La democracia participativa es una forma de democracia semidirecta, en la cual existen espacios destinados a la participación de los ciudadanos en la toma de decisiones del gobierno. En este modelo, el gobierno opera como un facilitador que promueve en los ciudadanos su capacidad de asociarse y organizarse a fin de que estos puedan tener una influencia directa en las decisiones públicas (Navarro, 2000). Este sistema ofrece al ciudadano una capacidad de participar en decisiones orientadas a desarrollar una economía socialmente justa y humanista, lo que a su vez promueve un ambiente de cooperación, apreciándose directamente las consecuencias de tales decisiones para todos y cada uno de los miembros de la sociedad (Correa, 2007).

Habermas (1989), plantea que la democracia implica crear un espacio público en que los ciudadanos puedan interactuar por medio de la discusión participativa sobre aspectos políticos y temas de interés común, desafiando verdades impuestas, exponiendo injusticias sociales e intentando generar cambios. La participación, en este sentido, es una forma de re-politizar el espacio público y desprivatizar la política, impidiendo que sea un monopolio de la esfera estatal o de una elite política (Falabella, 2008).

\section{Gobernanza de proximidad y partici- pación ciudadana en el espacio local}

En el contexto de la progresiva descentralización de las administraciones públicas en torno al gobierno local, se sitúa a las administraciones locales con roles estratégicos relevantes en el impulso y consolidación del desarrollo local desde perspectivas participativas (Vila, 1997, 2002). La descentralización local tiene entre sus retos elevar la calidad de vida de los ciudadanos, impulsar el tejido asociativo, desconcentrar la toma de decisiones, mejorar la profesionalización en la gestión de los centros y servicios municipales, aproximar el gobierno a la sociedad y viceversa, ampliar las estructuras y dinámicas participativas y luchar contra la exclusión de personas y territorios (Barreiro, 1999).

La proximidad municipal y descentralizada otorga mayores bases de legitimidad a los gobiernos locales, favorece el conocimiento de las necesidades de la población y ofrece mejores condiciones de satisfacerlas (Borja y Castells, 1999; Font, 2001). Pero esta proximidad debe estar vinculada a una ac- cesibilidad tangible de los procesos decisionales en igualdad de condiciones para todas las personas, grupos y organizaciones, evitando "acaparamientos" de poder y clientelismos políticos y técnicos. Este enfoque que se utiliza sobre participación ciudadana se refiere a la contribución que esta puede realizar a la gobernanza democrática.

La Unión Europea destaca cinco principios que constituyen la base de una buena gobernanza, estos son: apertura, participación, responsabilidad, eficacia y coherencia (Unión Europea, 2001). En este sentido gobernanza implica:

1. Una ampliación y pluralización de los actores de lo público, a causa de las transformaciones sociales e institucionales, incluyendo el Estado y "lo público no estatal" (Cunill Grau, 1997);

2. Un conjunto de procesos y arreglos institucionales conducentes a la coordinación de dichos actores plurales (negociación, deliberación, participación, concertación, alianzas, entre otros);

3. La construcción de metas comunes en el sentido de definidas colectivamente, vale decir no predeterminadas por uno de los actores o participantes de manera exclusiva;

4. Un tipo de respuesta efectiva y coherente a "entornos fragmentados y caracterizados por la incertidumbre" (Le Galés, 1998 citado en De la Maza, 2009: 3).

Este enfoque entiende que la legalidad democrática de las instituciones públicas se ha ido deteriorando ante una ciudadanía cada vez más reflexiva y crítica, con nuevos valores sociales que no pueden satisfacerse con la simple provisión directiva y tecnocrática de los servicios públicos (Blanco \& Goma, 2003 citado en Montecinos, 2007: 325). Por ello, esta perspectiva plantea la idea de un gobierno relacional que sitúa la gestión municipal en términos de deliberación e implicación ciudadana pluralista en las decisiones públicas locales. Esta idea intenta superar la concepción restringida de la gobernanza como marco de negociación de intereses entre grupos de presión, ya que reconoce los elementos de proximidad y de conformación de redes locales horizontales más allá de los intentos de reconstrucción de las capacidades estatales de gobierno (Montecinos, 2007). 


\section{Objetivos de la participación ciudada- na}

Con respecto a los objetivos de la participación ciudadana, se puede distinguir dos líneas de pensamiento (Mlynarz, et al, 2011). Por una parte, quienes plantean que la participación ciudadana es un medio para la consecución de un fin último; y por otra parte, quienes plantean que la participación ciudadana es un fin en sí mismo. En la misma línea, De la Maza (2009) considera que los objetivos de la participación ciudadana podrían combinarse con las etapas de la política pública, permitiendo estimar la prevalencia relativa de cada tipo de participación, distinguiendo entre las iniciativas surgidas como parte de las políticas y aquellas originadas por la sociedad civil. En el caso de las políticas públicas, distingue entre participación con objetivos instrumentales al diseño e implementación de las políticas; y por otra parte la participación empoderadora de la ciudadanía para la construcción de la gobernanza. La primera es aquella que se orienta principalmente a enriquecer y mejorar la política a través de procesos, y la segunda está centrada en la sociedad civil, por cuanto busca fortalecer sus capacidades y competencias (Ordóñez y Fernández, 2007).

\section{Mecanismos y niveles de participación ciudadana}

Existen diversos mecanismos ensayados en democracias actuales para afianzar la legitimidad en las decisiones políticas. Estas experiencias consisten en diversos métodos e instrumentos que posibilitan la ocurrencia de algún grado de participación ciudadana en la toma de decisiones, en donde confluyen agentes del Estado y organizaciones de la sociedad civil en torno a asuntos de política pública y diferentes formas (Font, 2001):

- Mecanismos de consulta a las comunidades: el formato más común que toman es el de consejo o comisión, y pueden ser de carácter territorial o sectorial. Pueden ser constituidos de diversas maneras ya sea desde la base social, desde organismos de gobierno o bajo una combinación de ambos.

- Mecanismos deliberativos: se presentan en dos grandes tipos, el primero busca la información y deliberación ciudadana y toma la forma de círculos de estudio, fórums temáticos y visiones de la comunidad, o conferencias de consenso. El segundo tipo se desarrolla en base a una selección de los representantes que los convierta en una muestra representativa de la sociedad y toman la forma de encuestas deliberativas, jurados ciudadanos, o paneles de ciudadanos.

- Mecanismos de democracia directa: manifiestan la voluntad de extender la participación y hacerla llegar al máximo posible a los ciudadanos, pueden tomar la forma de referéndums (Suiza y Estados Unidos), asambleas (gran Bretaña) y de algunos posibles usos de la tele democracia (Estados Unidos y Gran Bretaña).

- Otro tipo de mecanismos: corresponden a otras variantes con distintos nombres y pequeñas diferencias en los métodos organizativos utilizados, se presentan como participación ciudadana en la evaluación de los servicios públicos, encuestas de opinión y grupos de discusión (Gran Bretaña), mediación o elaboración de presupuestos municipales (Nueva Zelanda).

Estos mecanismos no son excluyentes entre sí, sino complementarios, siendo su interconexión lo que puede ofrecer aún mayores posibilidades a la participación que la suma de ellos. Sin embargo, los nuevos mecanismos de participación tienden a prestar mayor atención a la deliberación, tanto desde la participación directa como desde la representativa, principalmente cuando se trata de la toma de decisiones en temas de diseño de políticas públicas locales. La elección de un mecanismo dependerá de diversos factores: los recursos disponibles, las características del territorio, las experiencias participativas anteriores y sus resultados entre otras (De la Maza, 2009).

En relación a los niveles de participación ciudadana, estos pueden darse de diferentes formas y niveles (Arnstein, 1971): Nivel de información; nivel de consulta y debate; nivel de decisión; nivel de control; nivel de gestión compartida (Alberich, 1999; Pindado, 2000; Espadas, 2001). Por otra parte, Arnstein (1971) también distingue tres niveles en la intensidad de la participación, estos son el nivel informativo; nivel consultivo y nivel decisorio.

6. Incidencia de la participación ciudadana en políticas publicas La incidencia se puede entender como el grado y posibilidad de un grupo para influir en la definición, ejecución y evaluación de determinada política pública, teniendo en consideración la trama de posiciones jerarquizadas asignadas y asumidas por los diversos actores en materia de toma de decisiones. Esta surge como respuesta al elitismo y hermetismo en la formulación de políticas públicas, promoviendo mecanismos de deliberación pública y participación social (Torres, 2007, De la Maza, 2009). De esta manera, se puede distinguir analíticamente entre participación e incidencia, 
siendo ésta última el resultado visible y verificable de la primera (Anderson, 2002 citado en Hernández, 2007).

La participación o los procesos de participación pueden generarse desde al menos tres perspectivas:

- Arriba-Abajo: Promovida por la institucionalidad estatal, quien convoca a actores de la sociedad civil con el fin de cumplir con la normatividad jurídica, que incluye solicitar información, generar consultas o rendir cuentas.

- Abajo-Arriba: Corresponde a las acciones que nacen por iniciativa de la sociedad civil organizada y puede ser de carácter convencional o no convencional.

- Doble vía: Trata de buscar la aproximación y búsqueda de puntos de encuentro a partir de un reconocimiento mutuo de interlocutores legítimos entre representantes del aparato público y la ciudadanía organizada, y que tiende al establecimiento de acuerdos, toma de decisiones, gestión de programas y proyectos, y fiscalización de la acción gubernamental.

\section{Metodología}

Esta Investigación corresponde a un caso único y fue desarrollada a partir de un enfoque cualitativo de tipo descriptivo (Barrantes y Dorio, 2013). Se eligió el distrito VI del municipio de Managua, ya que es uno de los más grandes de la capital y con mayor importancia demográfica y económica dado su ubicación geográfica. Además, este Distrito es un canal institucional para canalizar los intereses políticos, económicos y sociales de la ciudadanía, por la proximidad que tiene con la comunidad.

Para desarrollar el proceso de recolección de información se recurrió a:

1. Revisión de fuentes bibliográficas y documentales (información secundaria) que permitió el abordaje de teorías y la exploración de resultados de otros estudios vinculados con el presente tema de investigación.

2. Como técnica de recolección de información primaria se utilizaron entrevistas semiestructuradas a informantes claves vinculados a la Alcaldía Municipal de Managua DistritoVI, donde se guió la conversación, utilizando una pauta de preguntas semi-estructuradas, grabaciones en formato digital y sugiriendo de manera previa la firma de consentimiento para el uso de la información proporcionada.
La selección de la unidad de análisis de esta investigación se desarrolló por medio de un muestreo deliberado de casos políticamente importantes y un muestreo por criterio basado a juicio del investigador, de acuerdo al propósito del estudio (Babbie et al., 2000). Los informantes no fueron escogidos al azar, sino que el investigador decidió dentro de un universo de actores relevantes en el Distrito VI, a quién entrevistar deliberadamente. De esta manera se rescató la percepción de funcionarios/as del Distrito VI de la Alcaldía de Managua, representantes políticos del distrito, sociedad civil y organizaciones comunitarias $^{4}$, distribuidos de la siguiente manera:

La información recabada a través de las entrevistas, se sometió a un proceso de ordenamiento a fin de situar los contenidos en torno a 4 dimensiones o categorías de análisis: análisis normativo de la participación ciudadana en el ámbito local, procesos de participación ciudadana en el Distrito VI, participación ciudadana en las políticas públicas locales y la incidencia de la participación ciudadana en el distrito VI. Posteriormente se definieron subcategorías para precisar información de conceptos y temas.

\section{Marco normativo de la partici- pación ciudadana en los Muni- cipios de Nicaragua}

\section{El poder ciudadano en Nicaragua}

\section{Concejos del Poder Ciudadano (CPC y GPC)}

Los Consejos y Gabinetes del Poder Ciudadano (CPC y GPC) fueron creados en el año 2007, por decreto presidencial (112-2007), como un nuevo mecanismo de democracia directa, que fomenta la participación ciudadana en el espacio local, con el fin de que la población nicaragüense se organice y participe en el desarrollo integral de la nación, de manera activa y directa, apoyando los planes y políticas del Presidente de la República (Stuart Almendárez, 2009). La implementación de este modelo descansa en tres pilares muy vinculantes: Gobierno, Partido y Comunidad.

\footnotetext{
${ }^{4} \mathrm{El}$ universo de estas organizaciones comunitarias es de 74 Gabinetes de la Familia conformados en 74 barrios del Distrito VI.
} 
Tabla 1: Selección de la Muestra

\begin{tabular}{|c|c|c|c|c|}
\hline No & Unidad de Análisis & Justificación & Entrevistado & Código \\
\hline 1 & $\begin{array}{l}\text { Gabinetes de la familia, la } \\
\text { comunidad y la vida del poder } \\
\text { ciudadano a nivel comunitario- } \\
\text { barrial. }\end{array}$ & $\begin{array}{l}\text { Representan el grupo de interés, de un universo de } 74 \\
\text { gabinetes de familia de barrios, con el fin de profundizar en su } \\
\text { conocimiento y experiencia en procesos de participación } \\
\text { ciudadana en el diseño de las políticas públicas en su localidad. }\end{array}$ & 17 & $\begin{array}{l}\text { G1:E1 } \\
\text { al } \\
\text { G1:E17 }\end{array}$ \\
\hline 2 & $\begin{array}{l}\text { Equipo de dirección de la } \\
\text { delegación distrital de la Alcaldía } \\
\text { de Managua (Delegada del } \\
\text { Distrito VI y Jefes de } \\
\text { Departamentos). }\end{array}$ & $\begin{array}{l}\text { Responsables de coordinar el trabajo con los gabinetes } \\
\text { comunitarios y la ciudadanía en general y transmitir la } \\
\text { información y propuestas para el diseño de políticas publicas a } \\
\text { la dirección superior de la Alcaldía y al consejo municipal. }\end{array}$ & 5 & $\begin{array}{l}\mathrm{G} 2: \mathrm{E} 1 \\
\mathrm{al} \\
\mathrm{G} 2: \mathrm{E} 5\end{array}$ \\
\hline 3 & $\begin{array}{l}\text { Secretaria el Consejo Municipal } \\
\text { de la Alcaldía de Managua. }\end{array}$ & $\begin{array}{l}\text { Representante de los concejales electos por votación popular } \\
\text { periodo } 2012-2016 \text {. }\end{array}$ & 1 & G3:E1 \\
\hline 4 & $\begin{array}{l}\text { Delegado del poder ciudadano } \\
\text { (Secretario Político del FSLN del } \\
\text { D-VI). }\end{array}$ & $\begin{array}{l}\text { Cargo Político Asignado por el Frente Sandinista de Liberación } \\
\text { Nacional, partido de gobierno. }\end{array}$ & 1 & G4:E1 \\
\hline \multirow[t]{2}{*}{5} & $\begin{array}{l}\text { Directores de Organizaciones de } \\
\text { la Sociedad Civil presentes en el } \\
\text { Distrito VI (INPRHU, INTERVIDA). }\end{array}$ & $\begin{array}{l}\text { Permiten conocer la visión de actores presentes en el distrito } \\
\text { respecto a los procesos de participación ciudadana en el diseño } \\
\text { de políticas públicas locales. }\end{array}$ & 2 & $\begin{array}{l}\text { G5:E1 } \\
\text { al } \\
\text { G5:E2 }\end{array}$ \\
\hline & & Total entrevistados & 26 & \\
\hline
\end{tabular}

Fuente: Elaboración propia

Criterios y mecanismos para la organización del poder ciudadano

Los niveles de organización de los consejos del poder ciudadano van desde la comarca hasta el nivel nacional. Existen cuatro niveles que organizan estos consejos: i) Nivel Base, ubicado en la comarca o barrio; ii) Nivel Distrital, iii) Nivel Municipal; iv) Nivel Departamental; y v) Nivel Nacional. Cada nivel delega representantes al nivel superior. A nivel de base, los representantes son electos entre miembros de la comunidad, sin embargo desde el nivel municipal los Gabinetes de Poder Comunitario son coordinados por profesionales del FSLN, designados además como delegados del poder ciudadano y delegados de gobierno. De ahí que la apertura ideológica que podría encontrarse en la base (Consejos del Poder Ciudadano) se estrecha a partir del municipio (GPC).

\section{Consejos de la Familia, la Comunidad y la Vida (CFCV y GFCV)}

La aprobación del código de la Familia de Nicaragua en el año 2013, se propone lograr un mejor protagonismo de las familias con acompañamiento institucional y de las organizaciones del poder ciudadano. La creación de consejos de familia en cada comarca, comunidad, Municipio y Departamento, permitió aportar al fortalecimiento de un modelo de presencia y participación protagónica de cada ciudadano en la trasformación de valores que se ex- presan en nuevas prácticas y formas de relacionarse entre mujeres y hombres, adultos y niños.

El gobierno se plantea la necesidad de rescatar valores familiares y promover la acción comunitaria para la transformación social, mediante procesos sencillos de discusión, reflexión y análisis que fortalezcan la autoconciencia de ciudadanía en relación de derechos y deberes. De igual manera el modelo sugiere el reconocimiento de capacidades para aportar y conducir procesos de transformación, personal, familiar y comunitaria para trabajar como protagonistas de esos procesos. El fin último de estos espacios de participación es que los ciudadanos adquieran compromisos concretos para sus propios procesos de cambio y de trabajo colectivo, creando entre todos una nueva Cultura de Convivencia, Fraternal, Solidaria, Complementaria, y de Mayorías Protagonistas.

La estructura de los Consejos de la Familia se divide en 5 niveles, de la misma manera que los Consejos del Poder Ciudadano. Sus dimensiones de trabajo se orientan hacia temas de promoción de valores familiares, restitución de derechos, temas productivos, temas de salud, educación, medio ambiente, culturales entre otros.

Los sectores interesados en la aplicación del modelo de participación ciudadana son: Gobierno central, incluyendo al ejecutivo, ministerios e instituciones de gobierno; Sociedad Civil organizada con incidencia a nivel nacional: INEH, CENIDH, CC; Partidos Políticos de Oposición: PLI, PLC, PC y MRS, agrupados de acuerdo a sus intereses ideológi- 
$\cos$.

En el plano de los sectores involucrados en la aplicación del modelo tenemos: Poder legislativo; Sociedad civil organizada con incidencia local y organizaciones emergentes agrupadas de acuerdo a intereses; Medios de comunicación tanto nacional como independientes.

En el plano de aplicación del modelo tenemos: Alcaldía municipal de Managua y en su defecto la delegación distrital VI; Ciudadanos que representan la población organizada y no organizada; Frente Sandinista de Liberación Nacional (FSLN) y toda su estructura organizacional; Los gabinetes de la familia, la comunidad y la vida.

En el centro del modelo de participación ciudadana se encuentran los gabinetes de la familia, la comunidad y la vida, alrededor de estos gabinetes están los ciudadanos, la Alcaldía Municipal de Managua (el Distrito VI) y el Frente Sandinista, la relación entre estos dos últimos es de cooperación mutua y bien acentuada, y la relación con los ciudadanos es de apoyo e interés. En este caso, la relación entre estos tres actores es la más importante, dado que es el escenario específico donde se pone en evidencia las prácticas de participación ciudadana a nivel municipal. No obstante, lo novedoso de esta relación es que hay un interés político fuerte por parte del partido de gobierno a fin de que se consolide este modelo a nivel comunitario.

A nivel municipal los GFCV constituyen un actor relevante y se ha puesto en la palestra pública. Tienen una capacidad de movilización, coordinación y articulación con actores comunitarios, bastante fuerte, lo que ha despertado el interés no solo de todos los actores sociales que se muestran en el mapa, sino también de la cooperación internacional.

Por otro lado, en el escenario medio nos encontramos con otro grupo de actores que están involucrados en la aplicación del modelo de participación ciudadana en dos direcciones: un grupo que brinda apoyo y aceptación del modelo entre ellos; medios de comunicación nacionales y el poder legislativo; y por otra parte un grupo de actores de la sociedad civil con incidencia más a nivel local, que se han manifestado activamente en contra de la aplicación de este modelo porque se siente excluidos en los espacios de participación, entre ellos tenemos a la Red Nicaragüense de la Sociedad Civil de Managua, organizaciones y movimientos sociales emergentes y los medios de comunicación independientes.

En este mismo escenario, existe un poder legislativo adormecido, posiblemente sesgado por una visión política ideológica del FSLN, el cual tiene un $70 \%$ de representatividad en escaños de diputación.
Ello implica una relación de apoyo e interés hacia la municipalidad y con los medios de comunicación nacionales en cuanto a la aplicación del modelo. Por otro lado se evidencia una relación de oposición con las organizaciones de la sociedad civil y organizaciones emergentes a nivel local (Managua), que cuestionan la parcialidad de los diputados y los procedimientos legales en cuanto a los mecanismos de participación y transparencia en la información a los ciudadanos. En este sentido se vislumbra una orientación vertical que emana desde el poder ejecutivo, hasta al a nivel municipal y de aquí, hasta la comunidad.

En un escenario más amplio tenemos al gobierno central, que tiene como objetivo la implementación y consolidación del modelo de participación ciudadana, con la idea de poder otorgar empoderamiento a la ciudadanía para la restitución de sus derechos sociales, económicos, políticos, ambientales etc.

\section{Instrumentos normativos para la par- ticipación ciudadana}

\section{Constitución Política de la Republica}

La Constitución Política de la República consagra un Estado de derecho basado en la democracia constitucional y que supone la soberanía popular, la formulación del derecho por la intervención o representación de los gobernados, la separación de poderes independientes, el reconocimiento de derechos y garantías individuales y sociales, la diversidad de grupos e ideas y la posibilidad asegurada de la alternancia pacifica en el acceso y ejercicio del poder (Cea, 1999). La soberanía nacional reside en el pueblo (art. 2), se reconoce a la persona, la familia y la comunidad como el origen del fin de la actividad del Estado (art. 4) y se consagra una democracia directa, participativa y representativa (art. 7). En cuanto a los derechos políticos, la constitución reconoce el derecho de ciudadanía (art. 47), el derecho de asociación (art. 49) y el derecho de participación (art. 50).

De acuerdo a los artículos antes señalados, la Constitución Política de la República de Nicaragua nos esboza la preponderancia que le da al ciudadano en la gestión pública como un binomio de democracia representativa y participativa. En ella se señala a los poderes del estado como depositarios de la soberanía popular por lo que sus funciones deben estar encaminadas a responder las expectativas y sentir de la población. Además hace referencia a dos sistemas de consulta y control ciudadano: el plebiscito y el referéndum. 


\section{Ley de Municipios (Ley 40)}

El municipio es el ámbito donde se puede dimensionar con mayor amplitud la gestión local y participación ciudadana (Obregón, 2013), ya que el ciudadano tiene un vínculo más directo con las autoridades, por ello la ley de municipio y sus reformas, resaltan la participación ciudadana como pilar fundamental para el desarrollo comunitario. El municipio es considerado en el art. 1, de la ley como la base político - administrativa del país, y sus elementos esenciales son: el territorio, la población y el gobierno. La Administración local de un municipio se radica en la municipalidad constituida por el Alcalde, quien es su máxima autoridad y a quien le corresponde su dirección y administración superior; y por el Consejo Municipal, órgano de carácter normativo, resolutivo y fiscalizador, encargado de hacer efectiva la participación de la comunidad local. Así pues, la ley en el art. 16, señala como derechos y obligaciones de los habitantes del municipio los aspectos de información, consulta y deliberación/co-gestión.

La máxima autoridad normativa del gobierno local lo constituye el Concejo Municipal, quien se encarga de establecer las directrices fundamentales de la gestión municipal en los asuntos económicos, políticos, sociales y ambientales del Municipio. Dentro de las atribuciones del consejo se destacan dos que son relevantes para este estudio de caso; a) la aprobación de la composición e integración de los Comités de Desarrollo para la planificación y ejecución de proyectos y obras municipales, tanto comunales como aquéllos que incidan en el desarrollo económico social del municipio y recibir informes periódicos de los avances en la ejecución de los mismos; y b) Aprobar la creación de las instancias administrativas y órganos complementarios de administración en el ámbito territorial del municipio, necesarias para fortalecer la participación de la población, mejorar la prestación de servicios e imprimir mayor eficacia en la gestión municipal. Dicha atribución se regulará en el manual de organización y funciones de la municipalidad. (Art. 28, numerales 7 y 13).

En este sentido el Municipio, en el ejercicio de su autonomía y en virtud del numeral 13 del artículo 28 , puede crear órganos complementarios de administración con el fin de fortalecer la participación de la población, mejorar la prestación de servicios y dar una mayor eficacia a la gestión municipal. Con el mismo propósito, el concejo municipal debe apoyar la creación de asociaciones de pobladores que tengan como fin el desarrollo municipal y fomentar la participación de las organizaciones y asociaciones sectoriales, culturales, gremiales, deportivas, profe- sionales y otras en la gestión municipal. Asimismo los ciudadanos, en forma individual o colectiva, gozarán del derecho de iniciativa para presentar Proyectos de Ordenanza y de Resolución ante el Concejo Municipal correspondiente. Se exceptúan los casos en que la iniciativa sea facultad exclusiva del Alcalde (Art. 37).

\section{Instrumentos y mecanismos de parti- cipación ciudadana}

De acuerdo a lo planteado por la ley, los municipios deben promover y estimular la participación ciudadana en la gestión local, mediante la relación estrecha y permanente de las autoridades y su ciudadanía, la definición y eficaz funcionamiento de mecanismos e instancias de participación, entre los cuales destacan los cabildos municipales y la participación en las sesiones de los concejos municipales y concejos municipales ampliados, que son de naturaleza pública. (Art. 36). En este sentido, en cada municipio se convocan los cabildos municipales, que son asambleas integradas por los pobladores, quienes participan sin impedimento alguno, de manera libre y voluntaria para conocer, criticar constructivamente y contribuir con la gestión municipal. Los cabildos son el resultado de un proceso asambleario de consulta popular permanente, generada desde cada barrio, comarca y/o comunidad, sobre las necesidades y expectativas de cualquier índole comunal. Los cabildos generalmente son presididos por el Alcalde y el Concejo Municipal y se elabora acta de celebración de los mismos.

La responsabilidad de promover estos cabildos es directamente del Consejo Municipal y del Alcalde, mediante convocatorias a los habitantes del municipio, sin embargo dada la complejidad del municipio de Managua en su división territorial por distritos, en cada distrito la garantizan los delegados del Alcalde y los gabinetes de la familia del poder ciudadano en el distrito correspondiente.

La ley describe dos clases de Cabildos: Ordinarios y Extraordinarios:

1. Cabildos ordinarios, en los cuales la ciudadanía se reúne cinco veces al año con el fin de discutir y aprobar el presupuesto municipal anual, así como para conocer el plan de desarrollo municipal, revisar e informar de la ejecución y cumplimiento del presupuesto municipal. Son de carácter obligatorio y son convocados, al menos con quince días de anticipación a su realización, por el Alcalde, por acuerdo del Concejo Municipal o a iniciativa de los pobladores.

2. Cabildos extraordinarios: son convocados con 
al menos 48 hrs de anticipación a su realización por el Acalde por acuerdo del Concejo Municipal o por iniciativa de la población. Se reunirán cuantas veces sean convocados para considerar asuntos que la población haya solicitado ser tratados públicamente y problemas y necesidades de la comunidad, con el fin de adecuar la gestión municipal y la participación de la población en la solución de los mismos.

\section{Ley de participación ciudadana (Ley 475)}

La ley de participación ciudadana promulgada en el año 2003, hace un reconocimiento explícito a las diversas formas de organización de la ciudadanía nicaragüense en la participación e incidencia en la gestión pública. Esta ley es un instrumento jurídico que tiene por objeto promover el ejercicio pleno de la ciudadanía en el ámbito político, social, económico y cultural mediante la creación y operación de mecanismos institucionales que permitan una interacción fluida entre el Estado y la sociedad nicaragüense, contribuyendo con ello al fortalecimiento de la libertad y la democracia participativa y representativa establecidas en la Constitución Política de la República.

Este conjunto de normas y regulaciones que se plantean en la ley, se fundamentan en los artículos 7 y 50 de la Constitución Política de la República, como expresión del reconocimiento de la democracia participativa y representativa, así como el derecho de participar en igualdad de condiciones en los asuntos de la gestión pública del Estado y en los instrumentos internacionales en materia de derechos humanos suscritos y ratificados por Nicaragua, aplicando los principios generales del derecho aceptados universalmente sobre esta materia.

\section{Principios rectores de la participación ciuda- dana}

El derecho de participación ciudadana establecido en la Constitución Política de la República, se rige de conformidad a los principios generales planteados en la ley, y que están transversalmente vinculados a los principios de la declaración del CLAD, en la Carta Iberoamericana de participación ciudadana en la gestión pública:

\section{Instrumentos de participación ciudadana}

Los instrumentos de participación ciudadana definidos en la ley son los siguientes: i) La iniciativa ciudadana; ii) La consulta ciudadana; iii) Las instancias consultivas para la formulación, seguimiento y evaluación de las políticas públicas en el ámbito nacional, regional autónomo, departamental y local; iv) Las asociaciones de pobladores y las organizaciones gremiales, sectoriales, sociales, organizaciones de mujeres y jóvenes en el ámbito local; y v) La consulta ciudadana en el ámbito local.

\section{Mecanismos de participación ciudadana}

En este ámbito nos encontramos que los gobiernos municipales tienen el deber de promover y estimular la participación de los pobladores en la gestión local para lo cual utilizan la realización de los cabildos municipales abiertos de conformidad a lo establecido en la ley de municipios. No obstante, los gobiernos locales podrán, de acuerdo a lo establecido en al arto 80, determinar por medio de ordenanzas de participación, las diferentes modalidades, mecanismos y plazos para la participación de los pobladores, en la elaboración, discusión y ejecución del plan o estrategia de desarrollo y plan de inversiones. Por otro lado la ley reconoce el derecho de petición y denuncia ciudadana como parte del proceso de participación, de forma individual o colectiva, de presentar de forma escrita solicitudes para realizar determinadas diligencias en virtud del cargo, siempre y cuando la petición esté vinculada directamente con sus funciones y de denunciar las irregularidades realizadas por los funcionarios públicos.

\section{Espacios de participación ciudadana para la formulación de políticas públicas}

La ley establece como espacios de partición ciudadana para la formulación de políticas públicas al Consejo Nacional de Planificación Social (CONPES), los Consejos Nacionales Sectoriales, los Consejos regionales de Planificación Económica y Social (CORPES), los Consejos de Desarrollo Departamentales y para el caso de los municipios los Comités de Desarrollo Municipal, para la cooperación en la gestión y planificación del desarrollo económico y social de su respectivo territorio de acuerdo a lo establecido en la ley de municipio en el art. 28 numeral 7.

Estos comités o consejos como la ley lo señala son organismos pluralistas, no ligados a los intereses partidarios, religiosos o de cualquier índole. De esta manera se garantiza la representatividad de los diferentes actores sociales del municipio y el gobierno municipal debe proporcionar los materiales mínimos necesarios para su funcionamiento. En este comité participan, representantes de los ministe- 
Tabla 2: Principios de la Ley 475 vinculados al derecho de participación

\begin{tabular}{l|l}
\hline \hline Principios & Descripción \\
\hline \hline Voluntariedad & $\begin{array}{l}\text { En tanto la participación ciudadana está reconocida como un derecho humano, ésta debe de } \\
\text { ser decisión inherente a la voluntad del ciudadano y con el claro y firme propósito de } \\
\text { participar voluntariamente y no mediante halagos, presión o coacción de interpósitas o } \\
\text { terceras personas, o bien porque la ley así lo establece. }\end{array}$ \\
\hline \hline Universalidad & $\begin{array}{l}\text { La participación ciudadana debe proporcionar al ciudadano la garantia, en igualdad de } \\
\text { condiciones a todos los ciudadanos nicaragüenses, sin distinción ni discriminación por } \\
\text { motivos de raza, sexo, edad, etnias, religión, condición social, política u otras razones que } \\
\text { pudiesen limitar el derecho a participar en los asuntos públicos y la gestión estatal. }\end{array}$ \\
\hline \hline $\begin{array}{l}\text { Institucionalidad } \\
\text { asumida y efectiva }\end{array}$ & $\begin{array}{l}\text { La participación ciudadana se institucionaliza y se convierte en un derecho exigible por la } \\
\text { ciudadania y en una obligación del Estado y sus representantes por tener que propiciar su } \\
\text { efectividad. }\end{array}$ \\
\hline \hline Equidad & $\begin{array}{l}\text { La participación ciudadana proporciona a todos los sectores de la sociedad, incluyendo } \\
\text { aquellos de mayor vulnerabilidad, los instrumentos jurídicos y políticos necesarios, para } \\
\text { colocarlos en un plano de igualdad con el objetivo de mejorar la condición y la calidad de } \\
\text { vida. }\end{array}$ \\
\hline \hline Pluralidad & $\begin{array}{l}\text { La participación ciudadana implica el reconocimiento de la diversidad de valores, opiniones } \\
\text { y prácticas dentro de la ciudadanía y el respeto a las mismas por parte de la autoridad, de } \\
\text { conformidad con el ordenamiento juridico. }\end{array}$ \\
\hline \hline Solidaridad: & $\begin{array}{l}\text { La participación ciudadana permite la expresión de los intereses superiores que llevan a la } \\
\text { ciudadanía a actuar en procura del bien común, más allá de los intereses particulares. }\end{array}$ \\
\hline \hline
\end{tabular}

Fuente: Elaboración propia a partir de la Ley 475

rios, representantes de la sociedad civil, representantes de los partidos políticos, representantes de la empresa privada, representantes religiosos y del consejo municipal.

Decreto creador de los consejos del poder ciudadano

Estos consejos y gabinetes del poder ciudadano tienen presencia en las comunidades, comarcas, barrios, distritos, municipios, departamentos, regiones autónomas y a nivel nacional. Los gabinetes pretenden contribuir de manera más efectiva a la solución de problemas comunitarios relacionados con cada sector, para ello cuentan con el acompañamiento de las instituciones del Estado y del gobierno local para proveerles de la información y conocimiento que les permita ser más proactivos en los procesos de participación que se ejercen desde su localidad y a la vez mejora la articulación e interacción con los actores locales.

El decreto también mandata, en al art. 3, la creación del gabinete nacional del poder ciudadano integrado por los consejos de poder ciudadano a través de un representante de cada uno de los dieciséis sectores antes mencionados, de cada uno de los quince departamentos y dos Regiones Autónomas existentes en el país. También podrán formar parte del mismo, representantes de los distintos sectores económicos y sociales del país que soliciten su participación y que la misma sea aprobada por dicho Gabinete. Dado lo anterior se reconoce que este gabinete es más bien una instancia de coordinación y articulación y no un mecanismo de participación como ha sido asumido y comprendido por la ciudadanía.

En este sentido el gabinete nacional del poder ciudadano será el resultado de un proceso organizativo según mandata el art. 5 del decreto, de la siguiente manera: i) Consejos comunitarios del poder ciudadano; ii) Gabinetes comarcales del poder ciudadano; iii) Gabinetes de barrios del poder ciudadano; iv) Gabinetes de distritos del poder ciudadano; v) Gabinetes municipales del poder ciudadano; vi) Gabinetes departamentales/regionales del poder ciudadano; vii) Gabinete nacional del poder ciudadano; viii) En todas las áreas y sectores que sean necesarias se podrán crear otros gabinetes. 


\section{Participación ciudadana en el D-VI del Municipio de Mana- gua}

\section{Percepciones de participación de los habitantes del Distrito VI}

El modelo del poder ciudadano en el distrito VI, tiene diversas concepciones, por un lado la ciudadanía la concibe como "una forma de trabajo con la comunidad y la familia, un modelo de participación en el cual las familias se constituyen en las protagonistas directas de su desarrollo [?] es un modelo incluyente que no excluye a nadie". (G4:E1). Desde la visión más institucional, se concibe como un instrumento que le permite a la municipalidad el diálogo o consenso con la comunidad, para incorporar su opinión en la toma de decisión para la formulación de proyectos a futuros. En este sentido se considera que es la población quien tiene el conocimiento certero de los problemas que viven a diario pues "ellos mismos exponen estos problemas y recomiendan la solución [...], por tanto la opinión e incorporación de la población para la formulación de proyectos o programas, así como la sostenibilidad de estos una vez finalizados, juega un papel muy fundamental en la gestión municipal". (G5:E2)

En opinión de 14, de los 17 representantes de gabinetes comunitarios entrevistados, la participación constituye un derecho ciudadano fundamental ya que "[?] son los ciudadanos los que construyen el cuerpo de una sociedad, los que forman parte de una comunidad y le dan vida a esa comunidad a la cual pertenecen" (G1:E8). Lo anterior está estrechamente relacionado con el arto. 4, 46 y 50 de la constitución política donde se reconoce la participación como un derecho inherente a la persona humana y reconoce al individuo, la familia y comunidad como el origen y fin de toda actividad, para asegurar el bien común.

Un elemento importante en esta investigación es que dentro del total de entrevistados de los gabinetes comunitarios, 3 de ellos asumen al participación, no desde una visión de derechos sino más bien, del sentido de pertenencia a la comunidad, de colaboración, apoyo y fraternidad. Ellos entienden la participación como aquellas acciones convencionales que se realizan en el ámbito de la comunidad para garantizar la limpieza, la prevención de enfermedades, promoción de la educación entre otras, las cuales son labores de concientización que si bien es cierto mejoran las condiciones de la comunidad, no son influyentes en temas de desarrollo local.

\section{Funciones de la participación ciudada- na en el gobierno local}

En cierto sentido estas funciones de participación definen una relación entre los ciudadanos y las autoridades municipales, así como algún reconocimiento de la capacidad y utilidad que el ejercicio participativo tiene para los intereses y expectativas tanto para los ciudadanos y el gobierno local. Sin embargo, uno de los dilemas más recurrentes según Cabrero (1999), es la búsqueda del equilibrio que permita al gobierno local incorporar un alto grado de participación, manteniendo la capacidad de regulación de la misma, generando los arreglos institucionales necesarios y siendo capaz de integrar la pluralidad de orientaciones en un proyecto consistente y con finalidades claras. Para ello Cabrero (1999) propone 4 funciones generales de participación ciudadana a partir de los cuales deben seleccionarse lo mecanismos adecuados derivados de los objetivos que se pretenden obtener del ejercicio participativo, en la siguiente tabla se muestran de manera sintética estas funciones.

De acuerdo a estas funciones de participación, el equipo de dirección de la delegación distrital de la Alcaldía entrevistados; consideran que la participación de los habitantes del Distrito es positiva desde los siguientes puntos de vista:

- Permite una adecuada identificación de las prioridades y necesidades de cada barrio

- Permite una adecuada selección de proyectos y por tanto una apropiada supervisión y ejecución de los mismos.

- Permite la posibilidad de lograr una mayor transparencia en la ejecución de fondos de la municipalidad que lleguen a cada barrio con calidad eficiencia y control.

En este sentido el plan estratégico de la delegación del Distrito VI, tiene un enfoque participativo en la medida que permite que el desarrollo económico y social del territorio, vaya de la mano con las prioridades de los barrios.

De acuerdo a las funciones de participación descritas por Vargas (2009 citado en Cabrero, 1999), y apoyándonos en la escalera de participación de Pindado (2000) y Espadas (2001), a partir de Arnstein (1971), describiremos los procesos de participación en el distrito VI del municipio de Managua tomando como referencias principalmente las funciones de consulta y cooperativa de participación y los niveles participación ciudadana en la información, consulta y decisoria de la escalera de Arnstein (1971). 
Tabla 3: Funciones de la participación ciudadana en el gobierno municipal

\begin{tabular}{|c|c|c|}
\hline Furioin & Dexipción & Mecarivmos o instrumintos \\
\hline Comsultiva & 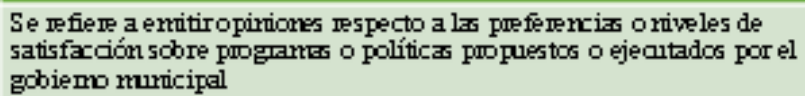 & $\begin{array}{l}\text { Sondeos de opirión, IPferénturrs, } \\
\text { plebiscitos, conrités o consejos }\end{array}$ \\
\hline Cooperativa & $\begin{array}{l}\text { Se refier a colaborar o cooperar enla realización de alaura obra de } \\
\text { carácter publico o enla prestaciónde algín servicio muricipal }\end{array}$ & $\begin{array}{l}\text { Correjos ygabinetes comuritaios, } \\
\text { xociariones de pobladores o integración } \\
\text { de OWGs. }\end{array}$ \\
\hline Decisoria & $\begin{array}{l}\text { Se refiere a contrbuiren el proceso de torra de decisiones no solo } \\
\text { enuitiendo opiriones, simo orientando las axciones del gobiemo } \\
\text { muricipal mediarte un poder de decisión. }\end{array}$ & $\begin{array}{l}\text { Integración de correjos y gabinetes } \\
\text { indadarcs o agentes sociales con } \\
\text { fanltades para dedir. }\end{array}$ \\
\hline Evahuación & $\begin{array}{l}\text { Se refiere a la evahuaióny seguiniento de las acciones del gob iemo } \\
\text { muricipal }\end{array}$ & 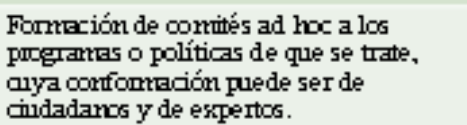 \\
\hline
\end{tabular}

Fuente: Marcos Iván Vargas (2009) citado en Cabrero (1999)

\section{Procesos de participación ciudadana en el distrito VI}

La práctica general de la Alcaldía de Managua en materia de consulta a la ciudadanía hasta el año 2007, fue mediante reuniones con líderes comunales y de organizaciones civiles, y delegados del Alcalde en las comarcas y con el Comité de Desarrollo Municipal (Serra Vásquez, 2010). En estas sesiones se presentaban las propuestas e iniciativas, normalmente de forma oral, y se dialogaba entre los presentes para recoger sus inquietudes. Las sugerencias eran retomadas o no, antes de pasar al Concejo $\mathrm{Mu}-$ nicipal para su aprobación final.

Los CDM fueron el principal espacio de concertación interinstitucional y de consulta de la gestión pública del gobierno municipal, un organismo pluralista y abierto cuya composición "reflejo y garantizo la representatividad de los diferentes actores sociales y formas organizativas del territorio" (Art. 55 Ley 475-03). Su rol primordial era la planificación municipal participativa en concertación con la autoridad municipal y la aprobación de los planes operativos y de inversión. Participaban también en el monitoreo y evaluación de dichos planes. Para el abordaje de los diferentes temas del desarrollo municipal, los CDM, contaban con mesas de trabajo temáticas o sectoriales, cuyo número y calidad dependían de las necesidades municipales.

No obstante, esta práctica de participación ciudadana dentro de los CDM, se traducían en espacios limitados de participación, es decir, no había un contacto directo con las bases, sino que se institucionalizó solo para aquellos que pertenecían a instituciones con personería jurídica, representantes del Estado y líderes comunales. Esto se manifiesta en la opinión de una entrevistada, cuando asegura que: "Había una representación minimizada en esa instancia (CDM) y la comunidad no estaba organiza- da ahí, no estaba realmente la voz de todas esas familias organizadas en cada uno de nuestros territorios" (G2:E1)

De esta manera surgen, a mediados del 2007, los GFCV como un mecanismo de participación ciudadana donde la gente se organiza a partir de sus necesidades y "a partir de las mismas formar una comisión de trabajo que es el gabinete de la familia para realizar sus gestiones en una institución de gobierno o de su municipalidad". (G4:E1).

15 de los coordinadores de los gabinetes comunitarios entrevistados, consideran que los GFCV contribuyen a resolver los problemas de la comunidad con programas y proyectos que generalmente están incluidos dentro de la programación del presupuesto asignado al distrito VI de la Alcaldía de Managua. No obstante pese al involucramiento de la ciudadanía en los temas sociales, esta aún se ubica en el nivel de información y consulta de acuerdo a lo planteado en la escalera de Arnstein (1971), pues como lo mencionaran los mismos coordinadores de gabinetes, estos funcionan como facilitadores de información y los insumos para que la alcaldía tome su mejor decisión e informe dónde, cómo y cuándo se realizaran los proyectos para las mejoras en los barrios del distrito. Este hecho se refleja en la opinión de uno de los coordinadores cuando expresan que: "Nunca nos han invitado a discutir sobre los programas y proyectos, porque cuando vienen aquí ya ellos traen trabajado todas y cada una de las actividades que se van a realizar". (G1:E14)

La delegación del distrito VI de la alcaldía de Managua de ninguna manera trata de atentar contra este derecho de participación en la gestión local, sino más bien de promover mecanismos de participación donde los ciudadanos pueda recibir información y tengan la oportunidad de opinar y proponer medidas para el diseño e implementación de las políticas públicas del distrito. Una de las accio- 
nes que realiza la delegación del distrito VI, es la atención directa a cada líder o coordinador de los gabinetes comunitarios de cada barrio. Esto les permite una mejor articulación del trabajo realizado y la promoción de asambleas que fortalezcan las acciones a tomar con mayor consenso. Los proyectos y programas impulsados desde el 2007 hasta la fecha, incluidos dentro del plan de inversión, han nacido de las prioridades de los barrios, para el acoplamiento a las líneas de desarrollo del gobierno dentro del Plan nacional de Desarrollo Humano (PNDH), orientadas a mejorar el desarrollo y calidad de vida de los habitantes del municipio. No obstante, en este proceso participativo los concejales electos por votación popular bajo los mecanismos de democracia directa, actúan como facilitadores desde los territorios para encausar las diferentes solicitudes a las prioridades definidas en cada barrio.

Es preciso señalar que este proceso de participación ciudadana que se vivencia entre los habitantes del distrito VI, se desarrolla a través de los instrumentos descritos en la ley 40, (ley de Municipios) y la Ley 475 (ley de participación ciudadana), donde se ejerce un proceso de interlocución con las autoridades a fin de vislumbrar situaciones de necesidades y problemática que tienen los habitantes y que puedan subir a la agenda pública. Estos instrumentos se traducen básicamente en la realización de asambleas y reuniones comunitarias y distritales para informar a la ciudadanía de las acciones a desarrollar en el distrito, así como la realización de cabildos participativos para la consulta e información ciudadana de las propuestas que realiza la comuna, lo cual a su vez representa un espacio para los ciudadanos para que puedan definir su intereses y plantear sus propuestas a los representantes de la municipalidad (Alcalde y Concejales) de los proyectos que desean en cada una de sus comunidades. Esto se evidencia en la opinión de organizaciones de la sociedad civil presentes en el distrito cuando expresan que: "nosotros participamos con la alcaldía en las consultas en los cabildos que se hacen con la ciudadanía para consultar el presupuesto, para proyectar acciones y obras [?] que se necesitan en la comunidad." (G5:E2)

Si bien es cierto que tanto en los cabildos consultivos como informativos, donde se discuten generalidades importantes con respecto a los proyectos a planificar y ejecutar, participan una representación de las comunidades del distrito, no asisten todos los ciudadanos, por lo cual las asambleas comunitarias son mucho más valoradas para la ciudadanía en la medida que pueden asistir una mayor cantidad de personas y discutir los problemas que atañen específicamente a su barrio, este hecho particular se evidencia en la opinión de uno de los entrevistados al decir que: "En los cabildos se plantea todo, pero solo llega a una representación de la ciudadanía [?] lo que le resta efectividad en los cabildos es que la gente no quede clara de lo ahí discutido, pero en la comunidad es diferente porque la población se interesa por el proyecto directo de la comunidad" (G1:E13).

Por otro lado, algunos de los planteamientos que los habitantes del distrito VI, hacen dentro de las reuniones programadas son de manera sencilla, sin un protocolo específico que impida la expresión ya sea verbal o escrita de la ciudadanía, estas se hacen a través del gabinete en pleno, se promueve a nivel de las familias y finalmente se formula un acta o documento que luego de no encontrarse respuesta a nivel local dentro de la cuadra, se eleva a las autoridades distritales de ser necesarios para la búsqueda de la solución a sus problemas.

\section{Mecanismos de participación ciudada- na implementados en el Distrito VI}

A raíz de la decisión del gobierno del Frente Sandinista en el año 2007 de promover la creación de los consejos y gabinetes del poder ciudadano a través de lo establecido en el decreto presidencial 1122007, las alcaldías municipales adoptaron esta iniciativa gubernamental a fin de fortalecer los procesos de participación ciudadana, sin detrimento a los derechos fundamentales de los ciudadanos descritos en el marco normativo de este estudio de caso. Estos se han convertido en el principal mecanismo de participación, deliberación ciudadana y de movilización social, que contribuye a mejorar y asegurar la transparencia en la gestión de recursos gubernamentales en la realización de los programas y proyectos que el gobierno está ejecutando. Su objetivo principal se fundamenta en lograr que: "[?] Las familias se sientan representadas e integradas para buscar de manera sencilla nuevas formas de vivir más humanas, más fraternas, más solidarias y que esto nos puede llevar a unos mejores éxitos como ciudadanía como humanidad como país" (G1:E10).

Los gabinetes de la familia en el distrito VI, se organizan en un proceso asambleario para definir responsabilidades, donde los habitantes de la comunidad eligen a mano alzada quién coordinará el gabinete y de la misma manera eligen representantes por sectores sociales que atiendan los interés de la comunidad en temáticas como salud, educación, medio ambiente, infraestructura, desastres naturales, etc. La agenda del gabinete conformado, depende básicamente de las necesidades comunitarias por lo cual se define una lista de prioridades para tratar de darles respuestas en un periodo no mayor de 3 meses con el acompañamiento institucional. 
Transcurrido este tiempo los habitantes vuelven a convocar a una asamblea para elegir sus nuevos representantes. No obstante, estos gabinetes tienen un desarrollo desigual en cada barrio o comunidad, pues esto básicamente depende de las características sociales y culturales del sector o del territorio, lo que representa un proceso en el cual se va avanzando a paso lento y donde los ciudadanos van tomando conciencia de que deben integrarse, sin embargo aún falta garantizar las condiciones más propicias para que esta expresión funcione de acuerdo a lo establecido en el decreto presidencial y en coherencia con lo definido en la ley de participación, este hecho se condice con lo expresado por uno de los coordinadores de los gabinetes entrevistado: "[?] ahorita no están dadas las condiciones como para integrarse [?] este proceso no ha logrado llegar a toda la población y la gente no toma conciencia verdaderamente que se tienen que integrar para defender la familia de toda problemática y tempestad" (G1:E12).

Dichas condiciones, dependen no solo de la voluntad política que tiene el gobierno actual, sino también de condiciones cada vez más complejas que exigen un mayor desarrollo legal de los mecanismos formales adherentes a los GFCV, así como también un proceso de aprendizaje de los mismos gabinetes comunitarios, en cuanto a los alcances del modelo, los instrumentos de ley y la compresión del funcionamiento de las instituciones públicas.

Estas expresiones de organización comunitaria en el VI, constituyen un elemento de complementariedad muy importante en la gestión municipal como un mecanismo de incursión desde una perspectiva económica, social y política al lograr que la ciudadanía desde sus comunidades "asuman compromisos de responsabilidad compartida" (G1:E8). La idea de responsabilidad social compartida nace por iniciativa de las instituciones gubernamentales y particularmente de las municipalidades de la necesidad de optimizar recursos para realizar más acciones en beneficio de la ciudadanía. En este sentido, los habitantes de las comunidades asumen compromisos para el desarrollo de ciertas acciones dentro de la comunidad.

Sin embargo, este tema aún se está trabajando para instalarse dentro de la comunidad, pues no todos los ciudadanos asumen compromisos ante un eventual programa o proyecto a desarrollarse en $\mathrm{su}$ barrio. Por su parte, las autoridades del Distrito VI buscan la manera de acompañar a la ciudadanía y concienciarlos en el tema de la disponibilidad de recursos, ya que como mencionaba el entrevistado, la coordinación con estos gabinetes ayuda a mejorar la gestión pública en tanto se logra articular de manera adecuada la oferta pública con las necesidades de la ciudadanía y a la vez esta asume compromi- sos de cooperación y apoyo en la implementación de los programas y proyectos que se ejecutan en el Distrito.

En opinión de los representantes de las ONGs entrevistadas, estos gabinetes han venido a consolidar la participación ciudadana de forma organizada en una entidad que se involucra y se apropia de las acciones dentro de la comunidad.

Dentro de este mecanismo de participación implementado en el distrito, se derivan los comités de auditoría social. Estos son comisiones conformadas por los gabinetes, en las cuales participa la comunidad para asegurar la transparencia en la ejecución de los recursos públicos y garantizar el cumplimiento de la calidad y condiciones pactadas cuando un determinado proyecto licitado por la municipalidad está en ejecución. Con esto se busca que los ciudadanos se sientan dueños del proyecto y satisfechos porque el proyecto que se realiza es lo que ellos. Sin embargo, a la comunidad como tal le cuesta involucrarse, debido al factor tiempo para estar pendiente del desarrollo de los proyectos en ejecución, no obstante el monitoreo y el cuidado que realizan es sumamente importante para lograr buenos resultados.

\section{Fortalezas y debilidades de los GFCV como mecanismos de participación}

Este modelo de participación ciudadana que se ejerce en el Distrito VI, presenta algunas fortalezas y debilidades en cuanto a la interrelación que existe entre las autoridades y los habitantes del distrito, es decir en ambas direcciones. La mayor fortaleza tiene que ver básicamente con la proximidad de la institución con la ciudadanía, por lo que fácilmente puede vehiculizar los intereses de sus habitantes hacia el nivel municipal de cara a abordar los problemas sociales que les aquejan.

Dentro de las debilidades señaladas por los coordinadores de los gabinetes comunitarios, la más importante se refiere a la calidad de la atención de los funcionarios en cuanto a las demandas o peticiones que estos realizan de manera continua y cuyo trato no se corresponde con las expectativas de los ciudadanos. "La verdad es que nosotros como gabinetes hemos sentido que no hemos sido bien atendidos en la delegación, hemos sido maltratados pero yo les digo a mi gente de la comunidad, que a veces no es llegar a imponerse sino que coordinar el trabajo con la alcaldía [?] y si no nos resuelve entonces hay como una inconformidad de la gente porque siente que sus peticiones no están siendo oídas" (G1:E10).

Este hecho se puede explicar porque los funcio- 
narios y trabajadores de la delegación distrital han estado acostumbrados a trabajar bajo una lógica convencional y este nuevo mecanismo de participación no tiene una real comprensión de sus alcances o en realidad nadie tiene muy claro para qué, lo cual está estrechamente relacionado con la opinión del secretario político del partido de gobierno, quien expresa que "el problema es que nuestros funcionarios todavía no están claros de la gran importancia y de la potencialidad que tiene este modelo" (G4:E1).

Otro elemento importante dentro de las debilidades encontradas es que los gabinetes comunitarios no cuentan con una formación adecuada de los instrumentos legales para poder realizar una participación efectiva, por tanto no conocen el funcionamiento de las instituciones y sus planteamientos y peticiones carecen de fuerza legal al momento de realizar sus demandas. Esto genera frustraciones y pérdida de confianza de los ciudadanos cuando la delegación no responde a sus necesidades, lo que generalmente desmotiva y hace perder el interés de la población en organizarse dentro de los gabinetes de la familia del poder ciudadano.

En la siguiente tabla se presentan un resumen de las principales fortalezas y debilidades de los gabinetes de la familia como mecanismos de participación ciudadana implementados en el distrito VI de la capital.

\section{Incidencia de los ciudadanos del D-VI en el diseño de políticas públicas}

En materia de políticas públicas, la participación es un bien que se distribuye de manera muy heterogénea, puesto que en cada una de sus fases o momento, operan distintos imperativos (legal, burocráticos-administrativo, consensual), y algunas veces estos son incompatibles o se contraponen con la inclusión de una perspectiva (Rein \& Rabinovitz, 1993). Lahera (2002), plantea 3 momentos analíticos del ciclo de políticas públicas correspondientes al diseño, Implementación y la evolución de la política.

Para este estudio de caso nos centraremos en el primer ciclo de la política que corresponde al origen del diseño, donde se evidencia una vinculación directa con los procesos de elaboración de agenda en la Alcaldía municipal de Managua, dado los mecanismos de participación descritos anteriormente con los que los usuarios pueden incidir en las características de la oferta, que incluyen desde la simple información hasta mecanismos de tipo más deliberativos adoptados por la comuna y que están definidos por la ley.
Según lo manifestado por el entrevistado (G2:E1), vemos una incidencia con una concepción un tanto de doble vía de las políticas públicas, puesto que desde arriba la acción del gobierno privilegia el trabajo de los expertos orientados a la decisión para la solución de problemas públicos y por otro lado, desde abajo, la comuna actúa en función de las presiones de los gabinetes comunitarios y procesa las demandas en políticas, lo cual se evidencia con el acompañamiento del equipo distrital al desarrollar capacidades y destrezas técnicas en los gabinetes comunitarios, tal y como son la elaboración de diagnósticos de problemas y levantamientos de censos comunitarios, con el fin de que estos puedan realizar propuestas viables y al mismo tiempo ejecutarlas.

Como alcaldía y como funcionarios estamos [?], para fomentar y contribuir a ese fortalecimiento comunitario donde la gente, la comunidad, el pueblo, los individuos y las familias participan, gestionan y son los protagonistas de todos esos avances y logros que van determinando ellos como prioridades en cada una de sus comunidades (G2:E1)

Cabe destacar que las delegaciones de la Alcaldía no cuentan con autonomía para la toma de decisiones en cuanto a problemas del territorio, sino que cumplen con el rol de recepcionar las demandas de la ciudadanía para transmitir la información a las autoridades de la comuna con poder de decisión (el Alcalde, Secretaría General y Consejo Municipal). No obstante, el equipo de funcionarios con competencias profesionales realiza propuestas de proyectos y programas para el territorio, de acuerdo al conocimiento y la experiencia adquirida con el trabajo realizado.

Uno de los roles fundamentales debe de partir de lo técnico, hacer propuestas técnicas que vayan acopladas a alineamientos técnicos a la municipalidad que permitan un desarrollo sostenible a las acciones del plan estratégico de infraestructura que debe de estar enfocado al desarrollo urbano de Managua, y lo segundo es articularlo con la población en situ y ver de qué manera podemos articularlo al desarrollo de Managua (G2:E5).

Desde la visión Distrital como delegación de la comuna, los alcances de esta incidencia desde arriba está orientada a apoyar la auto gestión de las comunidades, en la búsqueda de un ciudadano cada vez más propositivo y no demandante (que asuma derechos y también obligaciones) y de un gabinete que coordine y articule con la comuna los temas que atribuyen al desarrollo de su comunidad.

Por otro lado, desde la visión política del partido de gobierno (FSLN), la incidencia ciudadana debe 
Tabla 4: Fortalezas y debilidades de los GFCV como mecanismos de participación en el Distrito VI

\begin{tabular}{|c|c|c|}
\hline No. & Fortalezas & Debilidades \\
\hline 1 & $\begin{array}{l}\text { Los GFCV cucaran buenos niveles de } \\
\text { conunicación, coonfinación y coa el } \\
\text { acompalaniento de las autoridades de la } \\
\text { delegaciós distrital. }\end{array}$ & $\begin{array}{l}\text { E factor tiempo constituye un inconvenicabe al hacer } \\
\text { reuniones cousunitarias puesto que so permite que las } \\
\text { familias asistan por razones de trabajos. }\end{array}$ \\
\hline 2 & $\begin{array}{l}\text { Es ua espacio de participacion abierto amplio e } \\
\text { inclusivo so insportando credo, color o aspiración } \\
\text { politica. }\end{array}$ & $\begin{array}{l}\text { Poeo apoyo por parte de la ciodadania, cuando carecea } \\
\text { de respuestas por purte de la delegación distrital de la } \\
\text { alcaldia al planteamiento de sus aecesidades. }\end{array}$ \\
\hline 3 & $\begin{array}{l}\text { Promueve el rescate de valores dentro de la } \\
\text { conunidad. }\end{array}$ & $\begin{array}{l}\text { Los miembros del gabinete carecen de fonnació ea } \\
\text { aspectos institucionales, poe lo que no cooocen a pleaitud } \\
\text { el funcionamienso de la delegacion distrital. }\end{array}$ \\
\hline 4 & $\begin{array}{l}\text { Buscan la soducion a los problemas deste el seao } \\
\text { de la comunidad con el acompafamiento de las } \\
\text { instituciones del gebiemo presentes ea el distrito. }\end{array}$ & $\begin{array}{l}\text { Los camboos de nomenclatura de las expresiouses de } \\
\text { participación de CDM a conscjos del poder ciudadano y } \\
\text { a gabinetes de la familia, erean coafusiones en la } \\
\text { ciudadania. }\end{array}$ \\
\hline 5 & $\begin{array}{l}\text { Es un modelo de participacion ciudadana } \\
\text { vinculante y pernite el desarnollo del liderazgo } \\
\text { conunitario. }\end{array}$ & $\begin{array}{l}\text { E desinteres de los ciudadanos en involucrarse y } \\
\text { participar de los gabinetes por considerarlo wa } \\
\text { instrumento politico de gobierno y no con un carneter } \\
\text { independiente. }\end{array}$ \\
\hline 6 & $\begin{array}{l}\text { E compromiso ciudadano para asumir } \\
\text { respoosabilidades y desarrollar accioses deatro de } \\
\text { la comunidad y que facilitar el desarrollo de la } \\
\text { misma. }\end{array}$ & $\begin{array}{l}\text { Poca organizacion de los burrios, para gestionar ante las } \\
\text { municipalidades la realización de un proyecto o resolver } \\
\text { problemas propios de la consunidad. }\end{array}$ \\
\hline 7 & $\begin{array}{l}\text { Los GFCV respaldan la gestion mumicipal, en lo } \\
\text { social, politico, ea lo económico, en el desarrollo } \\
\text { de infraestructura. }\end{array}$ & $\begin{array}{l}\text { I a rotació de los coordinadores elegidos es eada } 3 \\
\text { meses, esto no les permise desarrollarse y potencializar } \\
\text { sus capacidades. }\end{array}$ \\
\hline 8 & $\begin{array}{l}\text { Los GHCV funcionan como un mecanismo de } \\
\text { control y audisoria social, que garantizan la } \\
\text { transparencia y la oricatacion de recursos a las } \\
\text { acesidades mas prioritarias. }\end{array}$ & $\begin{array}{l}\text { La delegacion distrital carece de un mecanismo de } \\
\text { monitorco y seguimiento pana los planteamicasos de los } \\
\text { gabinetes comunitarios y ua plan de acción para darle } \\
\text { respoesta. }\end{array}$ \\
\hline 9 & & $\begin{array}{l}\text { Los ciudadanos carecen de conocimieato de los } \\
\text { instrumentos legales y sécnices que limitan los aportes e } \\
\text { ideas que puode dar la comunidad para el discliko de } \\
\text { programas públicos. }\end{array}$ \\
\hline 10 & & $\begin{array}{l}\text { Funcionarios de la delegacion distrital todavia no estan } \\
\text { claros del funcionario, la importancia y la potencialidad } \\
\text { que ticase el modelo, so se dan cuenta que se deben a la } \\
\text { coenunidad y en ocasiones toman decisiones sia } \\
\text { coosular. }\end{array}$ \\
\hline
\end{tabular}

Fuente: Elaboración propia, a partir de las opiniones de los entrevistados.

orientarse a fortalecer las acciones de complementariedad, coordinación y articulación entre los gabinetes comunitarios y las instituciones de gobierno local, lo cual es coherente con la práctica del Distrito VI, en tanto se ha logrado hacerlo con los representantes de los gabinetes comunitarios. "Para que nuestro gobierno tenga fortaleza en el barrio y la gente sienta que el programa o proyecto está llegando a la comunidad, es que la comunidad asuma este reto de control social de acción complementaria de acción compartida" (G4: E1).

En opinión de las ONGs presentes en el Distrito VI, las políticas públicas son construcciones de todos los ciudadanos, no es una definición de un plan de gobierno (G5:E1). En este contexto, han venido trabajando en el fortalecimiento de organizaciones comunitarios a fin de que los ciudadanos conozcan lo que dicen las políticas públicas, para que sea la gente la que pueda tener las capacidades de hacer propuestas, asumirla, demandarla y evaluarla. No obstante, el proceso es difícil debido a que no hay mucha práctica del ejercicio ciudadano en Nicaragua. Lo antes descrito nos lleva a la pregunta de ¿quiénes son los que efectivamente puede participar e incidir en el diseño de las políticas públicas?

"Personalmente yo creo que los Gabinetes de la Familia son una oportunidad más para ser parte de la consulta, ser parte de movilizar, pero creo que hay otras expresiones que no están dentro de los gabinetes, que han llevado a la movilización y han ido planteando las incidencias" (G5:E1). Sin embargo, de acuerdo a lo planteado por el entrevistado no queda claro si estas expresiones organizativas presentes en la comunidad no participan dentro de los 
gabinetes, por una situación de intereses (no quieren hacerlo porque tienen otras prioridades) o bien no tienen las mismas capacidades para hacer sentir su voz y copar espacios de participación para la incidencia, este hecho es cuestionable si se piensa por ejemplo en la efectividad de los gabinetes de la familia como mecanismos de participación comunitaria.

Lo anterior se evidencia en palabras de uno de los representantes de los gabinetes al referirse que "Los gabinetes no se reúnen con nadie, solo son 2 o 3 personas, pero no hay mayor integración, yo no veo en las reuniones o en las comisiones que se hagan a la gente de la cuadra y la manzana promoviendo algo, solo un grupo pequeño de personas tratan de promover algo, dan a conocer la situación que se quiere promover y parte sin novedad" (G1:E12).

Los representantes de los gabinetes entrevistados consideran que pese al poco avance en el desarrollo de este modelo de participación ciudadana, estos contribuyen a que se vayan diseñando con más aciertos las políticas públicas en el gobierno local y se avance en el fortalecimiento de la familia y la comunidad (G1:E10; G1:E11), no obstante concuerdan que hay que mejorar los mecanismos por los cuales se inciden, haciendo más dinámica la institución (Delegación del Distrito VI de la Alcaldía), combinando adecuadamente el trabajo técnico de los funcionarios de la comuna y el conocimiento del territorio de los gabinetes comunitarios, en el sentido de que entre más participa la ciudadanía más se fortalece la municipalidad. Sin embargo para lograr esto, se requiere una mayor inserción de los gabinetes dentro del quehacer del Distrito, conocer más de la comuna y confiar en el quehacer de la comuna para que de manera conjunta se busquen solución a los problemas del territorio (G2:E4). "Los GFCV verdaderamente son la representación de la comunidad y creo que incide en el diseño de las políticas públicas, más bien creo que lo que debemos es mejorar la forma de su participación en pro del desarrollo comunitario" (G1:E17).

Parafraseando a Mlynarz, et al (2011), según lo antes expuesto por uno de los representantes de los gabinetes comunitarios, vemos que la información pública, es producida socialmente por los actores que participan de lo público, los cuales generan información que incide en alguna medida en la administración del sistema de decisiones públicas. Así podemos pensar que la información debe ser dinámica y fluir entre los ciudadanos y el distrito como enlace de la comuna de manera recíproca en las distintas etapas de la política pública que se implemente en el ámbito local, para que las acciones se correspondan a los intereses de la comunidad y se posibilite un desarrollo basado en requerimientos y propuestas de la comunidad.

\section{Retos y desafíos del sistema político en el diseño de políticas públicas}

Pese a los logros en el VI distrito, se desprende de las entrevistas que la Alcaldía de Managua y el sistema político en su conjunto deben enfrentar una serie de desafío y retos que se detallan a continuación:

- Lograr una mayor coherencia del modelo de participación ciudadana.

- Superar las diferencias políticas en cuanto al modelo.

- Lograr la autonomía social.

- Institucionalizar el modelo de participación ciudadana (Gabinetes de la Familia), con flexibilidad de diseño y pertinencia temática.

\section{CONCLUSIONES}

Los mecanismos de participación (GFCV), propuestos por el actual gobierno de Nicaragua, pretenden que los ciudadanos adquieran compromisos concretos para sus propios procesos de cambio y de trabajo colectivo, para crear entre todos una nueva cultura de convivencia, fraternal, solidaria, complementaria y de mayorías protagonistas, contando con el apoyo de las instituciones de gobierno y amparados por elementos normativos que tienden a institucionalizar estos mecanismos. De igual manera, lo novedoso de estos mecanismos es que se evidencia un interés político acentuado por parte del gobierno a fin de que logre su consolidación a nivel comunitario.

Sin embargo, dejando de lado el idealismo de gobierno, aún se cuestiona la pluralidad política de estos mecanismos de participación por parte de los diversos actores sociales y políticos, que no se sienten representados y se oponen ante una evidente desvinculación del proceso de participación entre lo que establece la ley de participación y lo que orienta el decreto presidencial 112-2007.

Ante las críticas y cuestionamientos sucesivos de los sectores de la sociedad civil, planteados en el análisis de los actores, se evidencia cierto nivel de captura política que no permite la inclusión de la sociedad civil en los procesos de participación ciudadana, para el diseño de políticas públicas locales. Por lo cual se requiere mayor apertura no solo del partido de gobierno, sino también de los partidos de oposición y la misma sociedad civil para negociar y 
ponerse de acuerdo sobre el funcionamiento y el fortalecimiento de estos gabinetes, que han mostrado de acuerdo a la experiencia, mucha fuerza movilizadora e interés por tratar de resolver los problemas dentro de la comunidad a pesar de no contar con la experticia suficiente en temas de mecanismos de participación ciudadana para el diseño de políticas públicas locales.

Por otro lado, los derechos constitucionales son reconocidos por la ciudadanía del Distrito VI, en tanto la participación ciudadana se establece dentro de la constitución como un derecho humano. Sin embargo, al contrastar lo establecido por la ley y lo que realmente se evidencia en la práctica ciudadana del distrito VI, se observa que los habitantes del territorio reconocen el derecho de participación y ciudadanía que la ley les otorga, pero no conocen los procedimientos y los alcances que tienen estos instrumentos y mecanismos de participación, lo que limita ampliar los niveles de participación dentro del ámbito local. De lo anterior se desprende que este nuevo sistema ha creado confusión y tensiones con el sistema legal, debido la duplicidad de las instancias de participación y la omisión de los espacios legales previstos por la ley de participación ciudadana, razón por la cual surge un trade off entre el ejercicio de participación dentro de los consejos de desarrollo local (CDM) y la participación de los ciudadanos dentro de los gabinetes de la familia, comunidad y vida (GFCV).

La evidencia empírica demuestra que los instrumentos o mecanismos de participación planteados por la ley son bastante formales y las relaciones de participación a nivel del distrito, se caracterizan por la proximidad con los ciudadanos, es por eso que los procesos de participación que se realizan, se hacen bajo las figuras de los gabinetes de familia del poder ciudadano, que si bien es cierto no tiene la misma formalidad que las consultas y no son vinculantes con lo normado, son un mecanismo más discreto y menos exigentes que funcionan mejor sobre asuntos de interés público para ponerse de acuerdo de los temas a nivel más local y ayudar a mejorar la gestión municipal.

Dentro de los procesos de participación ciudadana, encontramos que estos se construyen desde las bases territoriales, con una organización relativamente joven y en evolución, que se integra desde la cuadra y manzana en estructuras de gabinetes de familia hasta llegar a nivel de distrito y por ende a la alcaldía. Vale mencionar que los ciudadanos del Distrito VI, perciben la participación como un derecho ciudadano que dinamiza a la comunidad y las instituciones del gobierno local, convirtiéndose en un instrumento que le permite a la municipalidad el diálogo o consenso con la comunidad, para incorporar las opiniones de los ciudadanos en la toma de decisiones para la formulación de proyectos. En este sentido se vislumbra la participación ciudadana en el Distrito como una doble dimensión que se manifiesta en el ejercicio concreto de ciudadanía y al mismo tiempo como una acción política.

No obstante, aún persiste la noción de participación por parte de algunos representantes de los gabinetes comunitarios, como aquellas acciones convencionales que se realizan en el ámbito de la comunidad para garantizar la limpieza, la prevención de enfermedades, promoción de la educación entre otras, las cuales son labores de concientización que si bien es cierto mejoran las condiciones de la comunidad, no son influyentes en temas de desarrollo local.

A nivel institucional, la Delegación de la Alcaldía del Distrito VI, reconoce que la participación ciudadana es positiva en tanto le permite una apropiada identificación de las prioridades comunitarias, que contribuye a una mejor selección de proyectos, hechos que le permiten mejorar la gestión municipal y posibilitan una mayor transparencia en la ejecución de los fondos municipales. En este sentido, se reconoce el aporte de la participación ciudadana y la idea de un gobierno relacional (gobernanza de proximidad), que implica a la ciudadanía en las decisiones ya que ellos dentro de la comunidad son los que mejor saben lo que acontece en su territorio y por lo mismo pueden formar parte de las propuestas de la solución a sus problemas.

Las evidencias encontradas mediante las entrevistas, muestran que pese al involucramiento de la ciudadanía en los temas sociales, esta aún se ubica en el nivel de información y consulta de acuerdo a lo planteado en la escalera de Arnstein (1971). En este nivel de participación existe un proceso de interlocución con las autoridades a fin de vislumbrar situaciones de necesidades y problemáticas que tienen los habitantes y que puedan subir a la agenda pública. No obstante, la limitación más importante en estos procesos participativos es que están fuertemente concentrados en la fase de información de la política pública, lo cual indica una tendencia a utilizar la participación en las fases previas a la información y planificación.

En relación al ejercicio participativo implementado en el distrito VI, se ha avanzado progresivamente, reduciendo los problemas de participación básicamente vinculados con la capacidad del ámbito local, relacionados con la disponibilidad de recursos y la capacidad institucional, utilizando como instrumento o mecanismo de apoyo a los gabinetes de la familia del poder ciudadano, bajo la idea de la responsabilidad social compartida, lo cual hace 
que estos funcionen más como un mecanismos de articulación y gestión institucional para adecuar la oferta pública a las necesidades de las comunidades en el municipio y no como un mecanismo de participación propiamente dicho.

Dado lo antes descrito las evidencias muestran que la participación ciudadana en el distrito VI, cumplen con doble propósito, constituyéndose en una participación instrumental, en tanto contribuye al diseño de la política pública (no de formación de decisiones) y a la vez aporta al empoderamiento de la ciudadanía (en la fase de información) para una mejor gobernanza democrática.

La mayor fortaleza de este modelo de participación en el diseño de políticas públicas, es básicamente la proximidad de la institución con la ciudadanía, por lo que fácilmente puede vehiculizar los intereses de sus habitantes hacia el nivel municipal de cara a abordar los problemas sociales que les aquejan. Por otro lado, dentro de las debilidades encontradas tenemos que los funcionarios y trabajadores de la delegación distrital no tienen una real comprensión de los alcances de los gabinetes de familia como mecanismos de participación, lo que se traducen en una baja calidad en la atención de los funcionarios en cuanto a las demandas o peticiones de la ciudadanía.

Otro elemento importante dentro de las debilidades encontradas es que los gabinetes comunitarios no cuentan con una formación adecuada de los instrumentos legales para poder realizar una participación efectiva, por tanto sus planteamientos y peticiones carecen de fuerza legal al momento de realizar sus demandas. Lo anterior genera hasta cierto punto frustraciones y pérdida de confianza de los ciudadanos cuando la delegación no responde a sus necesidades, lo que generalmente desmotiva y hace perder el interés de la población en organizarse dentro de los gabinetes de la familia del poder ciudadano.

Con respecto al tema de incidencia en el diseño de políticas públicas, cabe destacar que las delegaciones de la Alcaldía no cuentan con autonomía para la toma de decisiones en cuanto a problemas del territorio, sino que cumplen con el rol de recepcionar las demandas de la ciudadanía para transmitir la información a las autoridades de la comuna con poder de decisión, sin embargo persiste una concepción de incidencia de doble vía, cuyos alcances están orientados a apoyar la auto gestión de las comunidades, en la búsqueda de un ciudadano cada vez más propositivo y no demandante (que asuma derechos y también obligaciones) y de un gabinete que coordine y articule con la comuna los temas que atribuyen al desarrollo de su comunidad.
Pese al poco avance en el desarrollo de este modelo de participación ciudadana, estos contribuyen a que se vayan diseñando con más aciertos las políticas públicas en el gobierno local y se avance en el fortalecimiento de la familia y la comunidad. Sin embargo, se deben mejorar los mecanismos por los cuales se incide, haciendo más dinámica la institución, combinando adecuadamente el trabajo técnico de los funcionarios de la comuna y el conocimiento del territorio de los gabinetes comunitarios, puesto que una mayor participación ciudadana fortalece la legitimidad de las acciones municipales. Sin embargo, para lograr esto se requiere una mayor inserción de los gabinetes dentro del que hacer del Distrito, conocer más de la comuna y confiar en el quehacer de la comuna para que de manera conjunta se busquen solución a los problemas del territorio.

Bajo estas premisas habrá que observar en el mediano y largo plazo el comportamiento de estos gabinetes de la familia en los espacios de participación local y los desafíos políticos que enfrenta el sistema, para mejorar la comunicación, la flexibilidad, la creación de conciencia y el fortalecimiento de estos espacios para el protagonismo de los ciudadanos en temas de diseño de políticas públicas que conlleven al desarrollo económico y social de sus comunidades, donde se configuran tres escenarios futuros a considerar:

1. Un escenario optimista en el mediano plazo, siempre y cuando continúe la tendencia de gobierno de turno en procesos democráticos. Tiene que ver con los desafíos políticos que enfrentaran los actores interesados en la aplicación del modelo en cuanto a lograr su consolidación, dándole la legalidad y legitimidad que requiere para el empoderamiento ciudadano. Este hecho podría mejorar los canales de participación establecidos por la ley, de tal manera que se logre la coherencia entre lo que mandata la carta magna y lo deseable según lo establece el decreto presidencial mencionado (decreto 112-2007). En este escenario, la fortaleza de los actores locales, junto a la voluntad política del gobierno central se conjugan, estableciendo mecanismos de consulta e intercambio político a fin de reorientar los aspectos estratégicos no solamente de la Política, sino también del proceso de participación ciudadana lo cual se convertiría en una verdadera negociación política entre los diferentes actores involucrados. De esta manera el ciudadano fortalecería su propia voz pública para participar de lo público y de lo político.

2. Por otro lado tenemos un escenario pesimista que tiene que ver con los actores involucrados 
en el plano de la aplicación del modelo, los cuales en alguna medida pueden sentirse excluidos y no aceptar el modelo de participación ciudadana por carecer de elementos que garanticen el respeto a los derechos ciudadanos, la pluralidad política y cultural, por considerar a los gabinetes de la familia como un espacio de participación con ciertos niveles de captura política, ya sea por un partido político concreto o por la reelección indefinida del presidente o el alcalde que pretenda imponer su propio estilo de liderazgo y de coordinación con las organizaciones de la sociedad civil basándose en la autonomía que le otorga la ley de municipio .

3. Otro escenario estaría dado si el gobierno de turno pierde las elecciones en el 2016 y el ejecutivo que asuma derogue el decreto que mandato conformar los consejos y gabinetes de la familia y reactive el funcionamiento de los consejos de desarrollo local establecidos por la ley de participación ciudadana. En este contexto los procesos de participación ciudadana, al margen de los procesos electorales, también podrían enfrentar el reto de poder superar la actual etapa de apatía de numerosos sectores de la población que rechazan el modelo. La cultura participativa en los asuntos público-políticos podría enfrentar de igual manera fuerte resistencia de los ciudadanos en relación a la utilidad de su participación, sobre todo frente a la posible falta de credibilidad en el gobierno de turno y el paulatino agotamiento de los líderes populares de los partidos de la oposición.

\section{Recomendaciones}

Dado los hallazgos encontrados en la presente investigación y considerando la opinión de los entrevistados, es posible plantear las siguientes recomendaciones:

Orientadas a la gestión municipal:

- Fortalecer el protagonismo de los gabinetes comunitarias desarrollando acciones que les provean de autonomía, de complementariedad y co-corresponsabilidad ciudadana. En este ámbito, podría pensarse en la elaboración de una ordenanza municipal que les otorgue la legalidad que requieren y la creación de una oficina que desarrolle programas específicos de participación ciudadana, que oriente y atienda las demandas de los gabinetes comunitarios y la ciudadanía en general.

- Descentralizar la realización de cabildos al ámbito más territorial, como una forma de transmitir la información a la ciudadanía, de modo que tengan más acceso a la misma y puedan participar en la toma de decisiones, para lo cual se requiere mejorar la convocatoria a los cabildos definiendo mecanismos de comunicación más efectivos que lleguen a todas las comunidades del Distrito, para ello podrían utilizarse los instrumentos más conocidos por la ciudadanía, como son las asambleas, reuniones de barrio, emisoras radiales locales etc.

- Dado que los Gabinetes de la Familia son un una organización comunitaria naciente, el gobierno local debe desarrollar un proceso de aprendizaje y formación para la ciudadanía, que le permita no solo el conocimiento de los instrumentos y mecanismos de participación ciudadana que mandata la ley, sino la manera adecuada de utilizarlos para los intereses colectivos del territorio.

- Desarrollar programas de capacitación en temas de gestión municipal y presupuestos municipales para la ciudadanía, para que conozcan más del municipio, su funcionamiento, de planes de inversión, de programas sociales y de recursos disponibles.

- Promover un mayor acercamiento de la institución con la ciudadanía en la comunidad, hacer que la institución se sienta en la comunidad, mediante la sensibilización de los funcionarios en la vocación de servicio, de modo que puedan transmitir su experiencia enfocada a las funciones que deben realizar en pro de la comunidad.

- Capacitar a los funcionarios municipales de los alcances del modelo de manera que puedan tener claridad de su función y del modelo que se está implementando y fortaleciendo, este hecho proveerá de mayores resultados en el proceso de incidencia ciudadana en el diseño de las políticas públicas locales.

- Reorientar el proceso de elección de representantes de gabinetes comunitarios a periodos más estables, de manera que permita un mejor desarrollo del gabinete y que les permita identificar y seleccionar no solo las prioridades del barrio sino también los compañeros que representante verdaderamente sus intereses, para que con autonomía puedan resolver los problemas que la comunidad demande.

Orientadas al diseño de política pública:

- Reformar la Ley de Participación Ciudadana, de manera que se puedan simplificar los ins- 
trumentos normativos (Ley 475 y Decreto 1122007), de modo que permita una adecuada articulación en las acciones de las organizaciones involucradas a través de un marco común y flexible, que permita a la ciudadanía elegir el mecanismo de participación ciudadana más apropiado, de acuerdo a los recursos disponibles, características del territorio y las experiencias participativas anteriores y además se pueda generar la planificación estratégica para la concreción del valor público en el mandato.

- Institucionalizar el nuevo modelo de participación ciudadana respetando la existencia de espacios y mecanismos no formales o espontáneos, respetando el carácter colectivo o individual de la participación.

- Los procesos de información amplia y actualizada sobre la gestión y las políticas institucionales son una condición necesaria para la participación eficaz y son importantes para la transparencia, por lo tanto se recomienda impulsar un proceso de modernización de la gestión municipal, mediante la creación de diversos procedimientos de participación ciudadana, incluyendo el acceso a las tecnologías de la información y comunicación y mecanismos de gobierno electrónico, donde la ciudadanía pueda opinar y consultar sobre temas de municipalismo.

- Orientadas a promover la agenda investigadora en el espacio local: Promover la investigación sobre la implementación de procesos de participación ciudadana en la implementación y la gestión de las políticas públicas locales.

- Evaluar la adaptabilidad institucional del modelo de participación ciudadana implementado en Nicaragua y sus implicaciones, considerando los escenarios futuros descritos en las conclusiones de este estudio de caso.

- Estudios que combinen tanto metodologías cuantitativas como cualitativas en temas de participación ciudadana en el espacio local y que permitan fortalecer el marco teórico de Participación ciudadana en Nicaragua.

\section{Referencias}

Alberich, T. (1999). Gestión pública, participación ciudadana y desarrollo local. Política y sociedad, $31: 163$.

Arnstein, S. (1971). A ladder of Citizen Participation. Journal of the Royal Planning Institute, pp. $1-6$.
Babbie, E., Halley, F., y Zaino, J. (2000). Adventures in Social Research. SAGE, Thousand Oaks, California.

Baño, R. (1997). Consideraciones acerca de la participación ciudadana. En Primer Seminario Conceptual sobre Participación Ciudadana y Evaluación de Políticas Públicas, Santiago. FLACSO.

Barrantes, R. y Dorio, I. (2013). Un camino al conocimiento, un enfoque cualitativo y cuantitativo. EUNED, San José.

Boeninger, E. (1984). Participación: oportunidades, dimensiones y requisitos para su desarrollo. Centro de Estudios del Desarrollo, Santiago.

Cabrero, E. (1999). Gerencia Pública Municipal, conceptos básicos y estudio de caso. CIDE-Miguel Ángel Porrúa, México D.F.

Campero, G. (2013). Apuntes de clases [Material de clase].

Cunill Grau, N. (1997). Repensando lo público a través de la sociedad. CLAD-Editorial Nueva Sociedad, Caracas.

Cunill Grau, N. (2004). Balance de la Participación Ciudadana en las Políticas Sociales. En Participación Ciudadana y Políticas Sociales en el Ámbito Local, pp. 57-76. IIS-UNAN, COMECSO, INDESOL, México D.F.

De la Maza, G. (2009). Tan lejos tan cerca. Políticas públicas y sociedad civil en Chile. Ediciones LOM, Santiago.

Espadas, M. A. (2001). La participación ciudadana en el Sistema de Servicios Sociales: Marco de referencia y perspectivas metodológicas para los programas de cooperación social. Nuevas perspectivas y líneas de investigación en torno al Trabajo Social, Universidad de Jaén. Comares, pp. 39-61.

Flisfisch, Á. (1980). Algunos problemas conceptuales en el análisis de la participación. En Seminario sobre Participación Social, p. 1, Quito. CEPAL.

Font, J. (2001). Ciudadanos y Decisiones Públicas. Ariel, Barcelona.

Lahera, E. (2002). Introducción a las políticas públicas. Fondo de Cultura Económica, Santiago.

Marshall, T. H. (1998). Ciudadanía y clase social. Alianza, Madrid.

Micco, S. (1997). [Comentario del artículo: Ciudadanía y Participación: notas para la discusión, de José Joaquín Brunner]. Avances de Actualidad, (28). 
Mlynarz, D., De la Fuente, G., Estévez, F., y Rammsy, C. (2011). nforme: Acceso a la información Pública y Participación Ciudadana. Technical report, Santiago.

Molina, N. (1997). Participación ciudadana, género y participación de la mujer. En Primer Seminario Conceptual sobre Participación Ciudadana y Evaluación de Politicas Públicas, Santiago. FLACSO.

Montecinos, E. (2007). Los límites de la modernización municipal para profundizar la participación ciudadana en Chile Â¿Es la Gobernanza de proximidad una alternativa? Gestión y Política Pública, XVI(002).
Pindado, F. (2000). La participación ciudadana en la vida de las ciudades. Ediciones del Serbal, Barcelona.

Serra Vásquez, L. (2010). Los retos de la participación ciudadana a nivel municipal en Nicaragua. $O S A L$, Año XI(27).

Stuart Almendárez, R. (2009). Consejos del poder ciudadano y gestión pública en Nicaragua. Centro de Estudios y Análisis Político, Managua.

Torres, R. M. (2007). Incidir en la educación. Polis [En Línea]. 